\title{
Vehicle with Counter Balance Controlling System
}

\author{
Design and Fabrication of Counter Balance Controlling System \\ Sweekriti Shukla \\ School of Mechanical Engineering, Galgotias University \\ Gr. Noida, India
}

\begin{abstract}
All vehicles are susceptible to rollovers to various extents. Light trucks roll at a lateral acceleration of 0.8 to $1.2 \mathrm{~g}$. Large commercial trucks roll at lateral acceleration as low as 0.2g. Trucks are more likely to roll over the passenger cars because they usually have taller bodies and higher ground clearance. Full-size vans don't usually have off-road suspensions, but their increased body height makes them prone to tip. Military vehicles have a much wider wheel track than civilian SUVs, making them more difficult to roll over. The rollover tendency is greater when the vehicle is heavily loaded. The rollover conditions occur due to various factors steering input, yaw rate, high speed, friction with ground, high centre of mass, or collision with an external object and digging the tyres into the soil. The objective of this experiment- based project is to design and fabricate an electromechanical counterbalance controlling system for vehicles to avoid rollover. This system mainly consists of a sliding rotary mechanism placed in the centre of the vehicle body frame having a heavy mass that can slide over it.
\end{abstract}

Keywords-Counterbalancing; Rollover; Tripped; Untripped; Rotary Sliding;

\section{INTRODUCTION}

India $2^{\text {nd }}$ largest population in the world, unfortunately ranks at the top with highest number of road casualties (about $11 \%$ share in the world). Road accidents has always been a leading cause of death, disabilities and hospitalization in the country. [1] The total number of road accidents related deaths in 2018 stood at 1,51,417 as per the Report on Road Accidents in India 2018. If we further categorize these road accidents according to the types of collision, we will come to know that the head on collision accidents share $18.7 \%$ which is the highest among all the type of collisions. Thus, this research paper is all about an experiment- based project that aims at reducing head on collisions with the aid of an electromechanical system for the counterbalancing of the vehicle.

\section{LITERATURE REVIEW}

A paper published by R.C. LIN Graduate Student, D. CEBON Lecturer and D.J. COLE Royal Society University Research Fellow [2] illustrates an investigation into active roll control of articulated vehicles. It tells us that to avoid rollover conditions in vehicles, the lateral load transfer must be minimized.

The methodology used to design lateral acceleration controllers for vehicles equipped with active anti- roll bars was developed using a simplified linear articulated vehicle model. The simulation results indicate the possibility of a significant improvement in transient roll performance of the vehicle, using a relatively low power system (i.e.10KW) with low bandwidth actuators.

Jack B. Ottestad [3] published a patent in which the counter balancing of the short wheelbase vehicle is discussed suggests us that an approach to solve the problem of rollover in vehicles is to provide an appropriate counterweight.

\section{CONTEXTUAL DESCRIPTION}

\section{A. Field of the project}

This project relates with the counterbalance controlling of vehicle. Rollovers occurs in 2 ways namely, tripped and untripped. Tripped rollovers are caused by forces from an external object for e.g. a curb or collision with another vehicle i.e. head on collision. An example of this rollover is when a vehicle leaves the roadway and slides sideways, digging its tires into soft soil or striking an object such as curb or guardrail. Untripped crashes are the result of vehicles dynamics such as steering input speed, friction with the ground. An example of untripped rollover is when a vehicle makes a collision avoidance maneuver or a cornering maneuver with high speed. [4] Nearly 35\% of passenger accident deaths are from rollover crashes. In vehicle stability control system, the active vehicle rollover prevention is there to prevent rollovers.

\section{B. Background of the project}

Several types of actuation systems can be used for rollover prevention. Among all the differential braking system has received the most attention from researches. It is used to prevent rollovers by reducing the yaw rate of the vehicle and the speed of the vehicle. By reducing the yaw rate and speed, the vehicle propensity to rollover is reduced. Also, steer by wire systems and active suspensions can potentially be used to prevent rollovers. Active rollover prevention systems have already been developed by several automotive manufacturers and are based on modifications of electronic stability control systems. These systems utilize lateral accelerometers to detect rollovers. But the drawback of these systems is that they can only predict and prevent untripped rollover. There has been no assistant system developed that can predict and prevent tripped rollover. Thus, this project is specifically made considering this drawback of systems that have been developed previously for the prevention of rollover.

\section{TECHNICAL DESCRIPTION}

After reading the various literature reviews, it would become obvious for one to conclude that a system should be 
essentially developed to prevent tripped rollover. So, this project model is constructed with the aim to reduce tripped rollover as well as untripped rollover in small 3 wheelers or 4 wheelers that are more prone to rollover.

\section{A. How this technique works?}

Since, this is an experiment-based project, so it is implemented on a nonmoving dummy vehicle instead of a realistic vehicle. This dummy vehicle is suspend hanged on an iron frame with the help of hinges and hollow pipe frame washer. Now, a sliding mechanism is constructed over the vehicle body frame which provides " $\mathrm{X}$ " and " $\mathrm{Y}$ " plus and minus sliding rotation. This sliding rotation is provided by two worm gear DC motors. A heavy mass (iron cubes) is placed on the sliding mechanism. These sliding mechanisms is placed on the center of the vehicle body frame. All this mechanism is controlled by an electronic circuit so that all these movements are sensed by an accelerometer sensor. The accelerometer senses the vehicle position with respect to ground surface. If vehicle faces high speed imbalance or any rollover condition, sensor immediately senses and informs the electronic controlling unit that immediately shifts mass to the opposite side for counter balancing.

\section{PROTOTYPE CONSTRUCTION}

- A 0.5-inch mild steel pipe and four plastic tires are used to construct the vehicle body frame.

- Now, the vehicle body frame is hanged to an iron frame with the help of hinges and hollow pipe.

- A rotary sliding mechanism is constructed over the model and a heavy mass is attached to it. This sliding mechanism is powered by two high speed worm gear DC motors.

- This rotary gear is controlled by a small electronic controlling circuit. This circuit is controlled by an accelerometer sensor.

- This accelerometer sensor always senses the vehicle position with respect to the ground surface. In case, the vehicle faces any rollover condition, the accelerometer informs the electronic controlling unit that controls the rpm of the worm gear motor required for the rotary sliding motion of the mechanism for counter balancing with the help of the movement of the heavy mass.

A. Components used

1) Mechanical components:
a) High speed worm gear DC motor
b) Pulley and sliding Mechanism:
c) Mild Steel Pipe
d) Wooden Base
e) Iron frame
f) Hinges
g) 8 Wheel rods
h) 4 Plastic Wheels: 10-inch thick plastic

\section{2) Electronic Components}
a) Low power( $1.8 \mathrm{~V}$ to $3.6 \mathrm{~V})$, ADXL335
Accelerometer
b) Controller
c) Relay
d) Transformer
e) Bridge Rectifiers
f) LCD
g) Regulator (7805IC in 5V power supply)
h) Switch
i) Jumper Wire
j) $\mathrm{PCB}$
k) Capacitors, Resistors, PNP transistor \& Diode
1) Choke Input Filter
m) Capacitor Input Filter

\section{B. Circuit diagram}

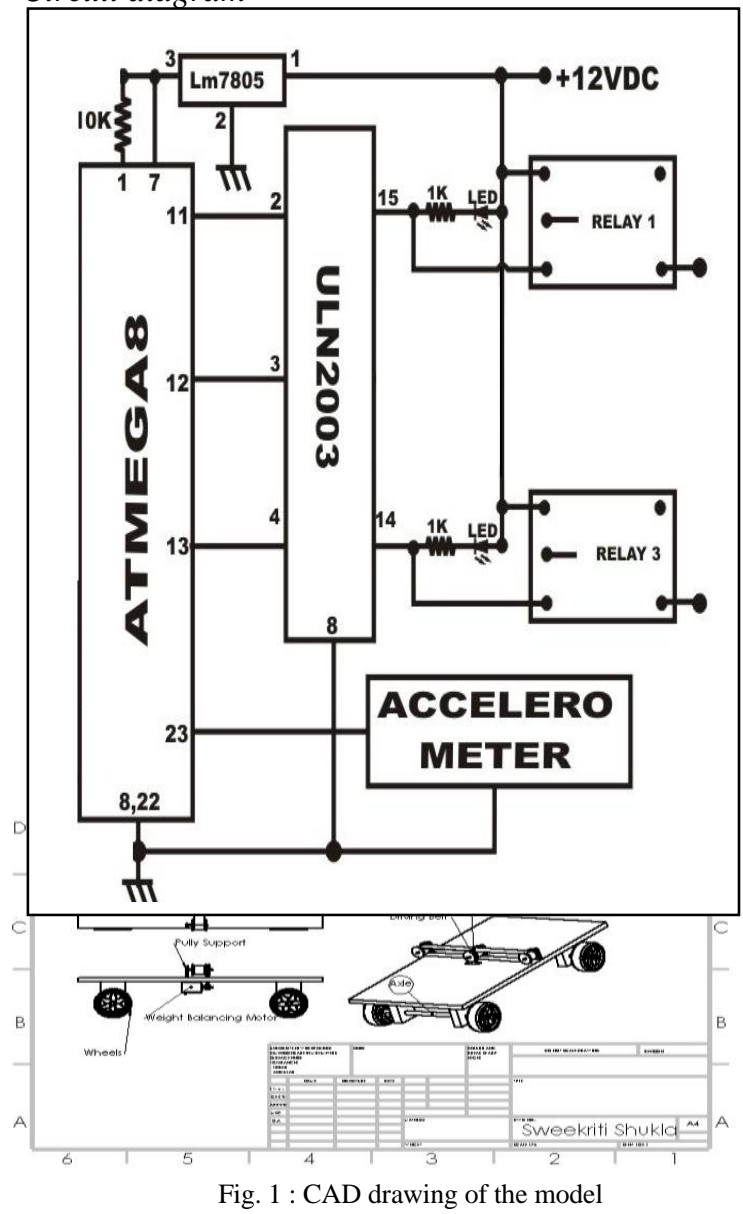




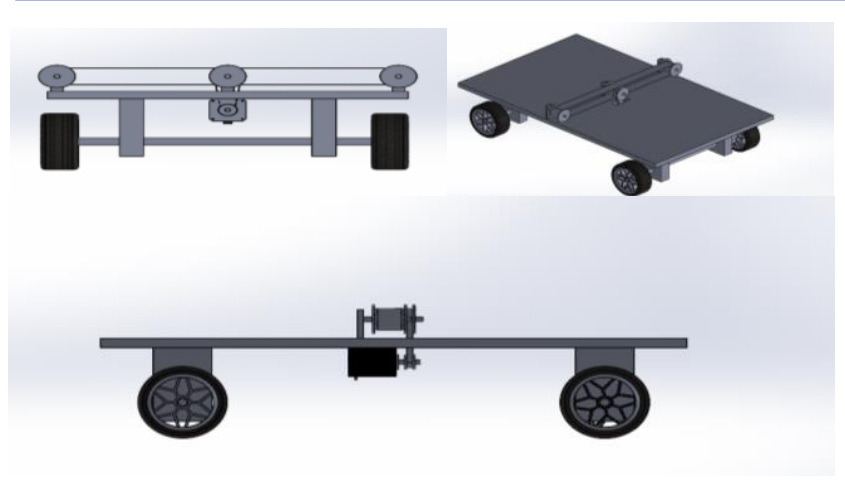

Fig.2: CAD Model

\section{APPLICATIONS}

This technique can be implemented in small vehicles such as three-wheeler autos or four wheelers like Tata Nano.
Since in these vehicles, there are no provisions for anti-roll prevention suspension due to their compact structure. Also, the installation of anti-roll suspensions in these vehicles is not justified in terms of cost. So, this rotary sliding counterbalance controlling system can be installed in these vehicles in the cockpit area

\section{REFERENCES}

[1] Ministry of Road Transport and Highways, "Road Accidents in India 2018", https://morth.nic.in/

[2] R. C. LIN Graduate Student, D. CEBON Lecturer \& D. J. COLE "An Investigation of Active Roll Control of Heavy Road Vehicles", Vehicle System Dynamics, Volume 23, 1994 - Issue sup1

[3] Jack B. Ottestad, "Counterbalance system for short wheelbase vehicles", JUSTIA Patents.

[4] Kailerk Treetipsounthorn, Gridsada Phanomchoeng, "Real Time Rollover Warning in Tripped and Untripped Rollovers with a Neutral Network”, IEEE, ISBN: 978-1-5386-7887-9 